\title{
PREVENTION AND HEALTH PROMOTION AT THE WORKPLACE AS A PART OF PRIVATE MEDICAL CARE FOR EMPLOYEES IN POLAND - AN OVERVIEW
}

\author{
Agata Suchańska ${ }^{1}$, Andrzej Marcinkiewicz ${ }^{2}$ \\ ${ }^{1}$ Medical University of Warsaw, Warsaw, Poland \\ Faculty of Health Sciences, Public Health Institute \\ ${ }^{2}$ Nofer Institute for Occupational Medicine, Łódź, Poland \\ Center for the Education of Physicians in Public Health
}

\begin{abstract}
This review includes information about the number of private health insurance and medical subscriptions in Poland, as well as the level of increases in premium rates, and the scale of health promotion and prevention conducted by Polish employers. The aim of this article is to present the current situation on the supplementary private medical market, which is involved in employees' healthcare, and the challenges that both employers and medical providers with health insurers are now facing, and also to present the reasons why prevention and health promotion are important factors of healthcare under private health insurance. For the purpose of this review, scientific publications devoted to health promotion at the workplace were used, along with statistical data presented in the studies released by the Polish Insurance Association, the Polish Social Security Institution, the World Health Organization and the Organization for Economic Co-operation and Development. The literature search was carried out using the electronic databases of PubMed. Search terms included medical subject headings and free text words. No year of publication restriction was imposed. The conducted analysis shows that the demand for private medical care is rising. Employers are willing to invest in private medical care for their employees, although the scale is much lower among small and medium-sized entrepreneurs due to fiscal burdens. Given the rising demand and an insufficient number of specialists, access to medical services is deteriorating, and the premium rates and costs are rising. More employers are investing in health promotion at the workplace in order to decrease absenteeism and presenteeism, lower the utilization of medical packages, and improve their attractiveness on the market. Although the interest in private medical care is rising, employers should focus on health promotion and prevention at the workplace, and adapt their actions to the employees' current needs and health issues. Med Pr. 2020;71(6):735-42
\end{abstract}

Key words: health promotion, occupational health, occupational health service, additional health insurance, health benefit plans, private medical market

Corresponding author: Agata Suchańska, Medical University of Warsaw, Public Health Institution, Nielubowicza 5, 02-097 Warsaw, Poland, e-mail: aolearczyk@wum.edu.pl

Received: December 9, 2019, accepted: February 11, 2020

\section{INTRODUCTION}

Each year, the number of people using private medical care in Poland is growing. This is evidenced by the constantly increasing number of people with private health insurance enabling non-cash delivery of services in private medical facilities. According to data published by the Polish Insurance Association (PIU), at the end of 2018, over 2.6 million Poles had already benefited from private health insurance (not including medical subscriptions). In 2018, the number of people with additional health insurance increased by $23 \%$ and the premiums collected by insurance companies by $20 \%$, with Poles spending over PLN 821 million on private health insurance in annual terms [1]. This amount applies both to individual policies as well as group programs offered by employers as employee benefits. In order to get the bigger picture, one should also add the number of people with private medical subscriptions (which is a different type of a contract provided by medical companies), which is estimated to be similar. According to information collected by the Polish Central Statistical Office (GUS), as early as in 2016, 5.9\% of Poles had already benefited from private health insurance or medical subscriptions [2]. This clearly shows that Poles are eager to opt for private health insurance in order to gain better access to many medical services.

The main reason driving the increasing interest in private health insurance is a poor condition of the public healthcare system. According to the survey conducted by the Public Opinion Research Center in Poland (CBOS), $66 \%$ of respondents assessed healthcare 
in Poland negatively [3], and the main factor was the long waiting time for services. Better and faster access to services is, therefore, the main reason for using private medical care for $88 \%$ of respondents. Among other reasons for using private medical care instead of public are a better attitude of doctors to patients (58.8\%), a better quality of medical equipment $(52,5 \%)$, better infrastructure of the medical facility (40.7\%), and a better quality of patient service (37.9\%).

While discussing the subject of availability, it is worth to mention the current data of the Watch Health Care (WHC) Barometer, according to which the average waiting time for medical services in Poland extended to 3.8 months at the beginning of 2019 (comparing to 3.7 months in May 2018). However, for many services it is much longer. For example, the average waiting time for an appointment with an endocrinologist is 11.6 months (while the longest waiting time for this service was 24.2 months). In turn, the greatest deterioration in access was recorded in orthopedics and traumatology - an extension of 3.3 months comparing to the previous year (from 7.7 months in May 2018 to 11 months in January 2019) [4].

The aforementioned CBOS research also shows that almost $60 \%$ of employees in Poland want to receive private medical care from their employer, and they are willing to pay for it. In the "Payroll report for 2018" by Hays, $65 \%$ of respondents indicated extended private medical care as the most desirable employee benefit. In the analysis conducted on the pracuj.pl portal, medical care is in the third place when it comes to benefits encouraging one to change his/her job (62\%) [5].

The aim of this article is to present the current situation on the supplementary private medical market, which is involved in employees' healthcare, and the challenges that both employers and medical providers with health insurers are now facing, and also to present the reasons why prevention and health promotion are important factors of healthcare under private health insurance.

\section{METHODS}

The literature search was carried out using the electronic database of PubMed, and included articles in English and Polish. Search terms included medical subject headings and free text words. No year of publication restriction was imposed.

Secondly, the review included statistical data presented in the studies released by government and non- government organizations, both Polish and worldwide: the aforementioned PIU, the Polish Social Security Institution (ZUS), GUS, the World Health Organization (WHO), the Supreme Audit Office (NIK), the Organization for Economic Co-operation and Development (OECD), CBOS, and reports of insurance brokers dated 2016-2019: Mercer (Poland), Willis Towers Watson (WTW), and Aon Hewitt (AON).

Some publications were searched through a Google browser by words in the English and Polish equivalents: health promotion at the workplace, wellness programs, occupational health, workplace health, healthcare at work, employee health and employee lifestyle. The first 2 pages of articles were taken into account that best matched the search terms.

The review also included data provided directly on websites and presenting internal research and data, as well as reports available online, such as pracuj.pl, WHC Barometer on the website, the Lesław A. Paga Foundation website, and the European Health Interview Survey 2014.

The last type of the sources used in the article are laws and regulations related to the subject of this review, valid as of November 24, 2019.

\section{RESULTS}

The conducted analysis confirms that private medical care is currently a significant tool for employers, both in terms of recruiting and retaining employees. Private medical packages are mostly offered due to mandatory occupational health check-ups. In accordance with the Polish Occupational Medicine Act, all employers are obligated to cover their employees with prophylactic healthcare. The employers' obligations include preliminary, control and periodic examinations. The scope of such examinations is in accordance with exposures at the workplace. Moreover, employers should initiate and implement health promotion, especially preventive health programs resulting from an assessment of the employees' health condition [6]. Due to its obligatory nature, occupational medicine should definitely be used in preventive actions, covering the entire employee population in Poland, e.g., by extending the panel of laboratory tests by cholesterol measurements for all employees, regardless of their position and occupational exposure. Given the fact that, over time, many new factors have emerged, such as changing demographics (increasing diversity), aging workforce, globalization and climate change, occupational medicine is facing new challenges and should progress [7]. 


\section{Occupational medicine in the private package}

The above obligation gave medical and insurance companies an opportunity to sell occupational medicine as a product - stand-alone or as a complex medical package. On top of occupational health services, companies add other medical services, including specialist consultations, laboratory and diagnostic tests, and even physiotherapy and dental treatment.

Medical services are exempt from goods and services tax (VAT). The part priced as occupational health services can be paid only by the employer as, under the reference Act, employees cannot bear the costs of occupational health services. Therefore, the remaining price for medical services is added to the employee's salary which, due to the fact that private medical care as a benefit is treated as the employee's income, is subject to the employee's income tax and social security contribution.

The financing of private medical care by employers for employees, and sometimes also for their family members, has become standard on the Polish market. According to the Mercer Total Remuneration Survey, the number of companies financing private medical care for their employees is steadily increasing and maintaining a high level $-89 \%$ in $2019(\mathrm{~N}=426)$ [8]. Comparing to other European countries, private medical care sponsored by employers is much more popular in Poland than in Hungary, Austria, the Czech Republic, Slovakia, Lithuania or Denmark [8].

On the other hand, according to a report prepared by the Marketing Research Center INDICATOR, as commissioned by PIU, $68 \%$ of small entrepreneurs do not provide their employees with a private medical package. Financial reasons are indicated as the main factor by $34 \%$ of respondents, due to the high financial burden resulting from mandatory ZUS contributions [1]. The legislative system in Poland lacks regulations that would remove the full fiscal burden on companies offering their employees additional private medical care and health promotion. Economic incentives (subsidies, sanctions or insurance incentives) are used in many European countries, which motivates employers to take preventive actions and to promote health and safety at work [9].

Although it is not a comprehensive solution, some companies implement an additional solution, i.e., the optimization of social security contributions. By guaranteeing employees medical packages with partial payment required from them, the total price of a medical package does not constitute the basis for calculating social and health insurance contributions, but only in- come tax. An additional condition is that such a benefit results from a collective labor agreement or remuneration regulations [10]. The optimization mechanism is presented in Figures 1 and 2.

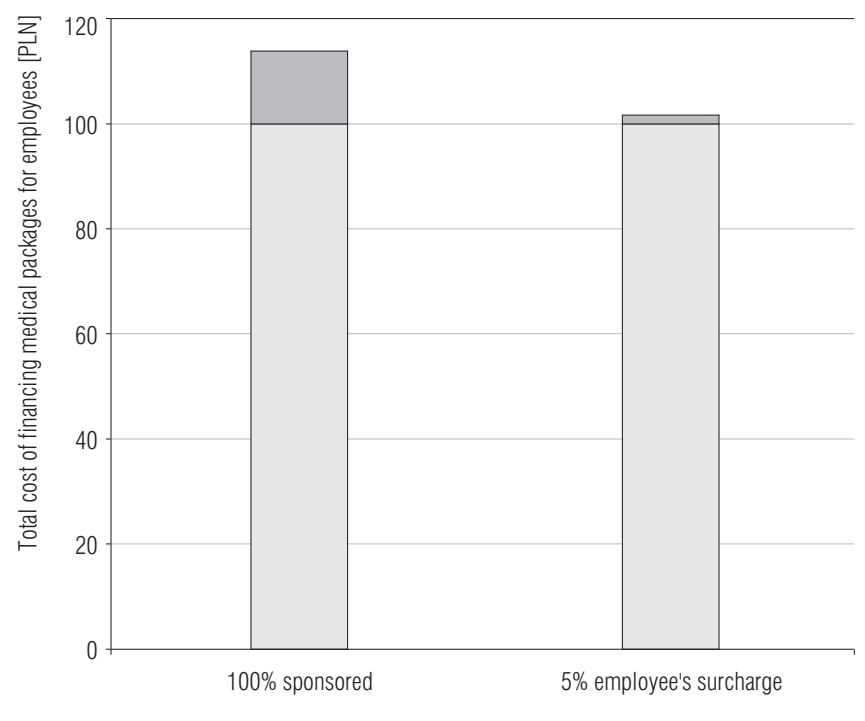

$\square$ cost of medical package

$\square$ ZUS and funds: the labor fund and the guaranteed employee benefits fund

ZUS - Social Security Institution.

Figure 1. Social security contribution (SSC) optimization mechanism - the employer's perspective

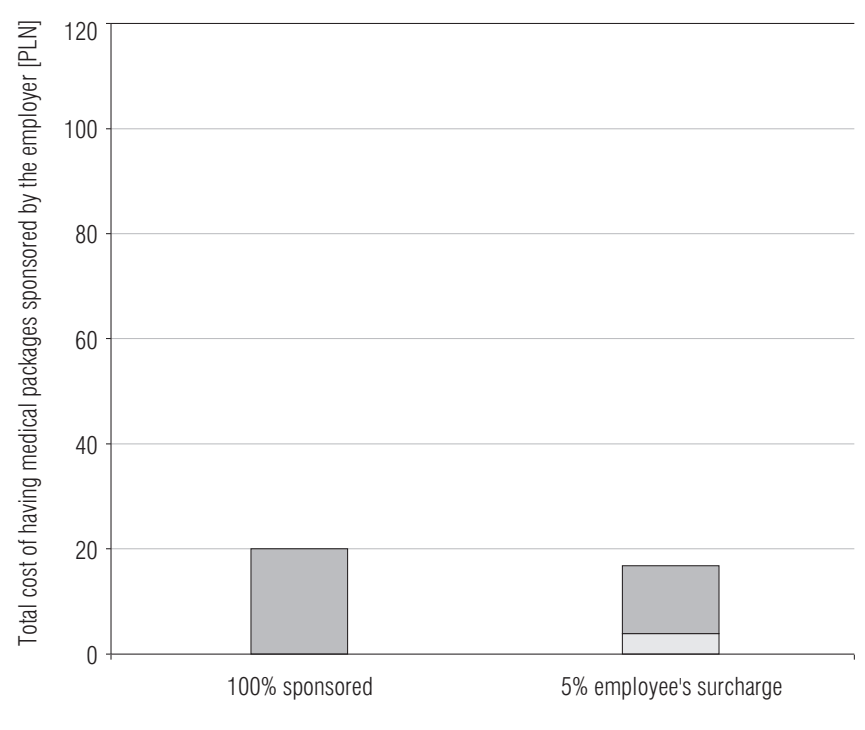

$\square$ surcharge

Scenario before and after SSC optimization

$\square$ ZUS and income tax

ZUS - Social Security Institution

Figure 2. Social security contribution (SSC) optimization mechanism - the employee's perspective 


\section{Private medical care as a tool for sickness absence management}

However, private medical care and health promotion can also bring an economically measurable return and be one of the elements of sickness absence management at the workplace [11], by decreasing absenteeism and presenteeism, increasing productivity, engagement and well-being of employees, as well as making the company's image even more attractive [12].

According to a report by ZUS, in 2018 Poles spent over 277 million days on sick leaves, and the average length of a sick leave was 12.88 days [13]. The most common diseases causing absenteeism, in terms of the number of days, were pregnancy, childbirth and puerperium (19\%), muscoskeletal system diseases (15.4\%), injuries, poisonings and other specific effects of external factors (13.8\%), respiratory system diseases (13.5\%), as well as mental and behavioral disorders (8\%). As regards the last factor, the increase in the number of sick leave days appears disturbing. In 2012-2016, an increase of 35.5\% was recorded, and the share of these disorders in total expenditure was $9.8 \%$ among men and $9.2 \%$ among women [14].

The costs incurred by ZUS due to sick leaves exceeded PLN 16 billion. One should not forget about the costs suffered by employers both due to employee absenteeism and presenteeism, the later being defined as the presence at work despite an illness, with lower productivity and efficiency. Both situations trigger high direct costs (hiring a substitute, production downtime, order delays) and indirect costs which are more difficult to calculate (the time spent on recruitment, slower work of a lower quality, a higher risk of mistakes, infecting other employees).

Undoubtedly, the scale of employees on sick leaves has a significant impact on the economic situation of the country. For example, the costs of heart failure in 2015 amounted to PLN 3.9 billion [15]. In turn, ZUS expenditure on benefits related to the inability to work due to type 2 diabetes amounted to nearly PLN 120 billion in 2016, and the total costs of treating sick patients under the National Health Fund amounted to PLN 1.7 billion (by $8.5 \%$ more than in 2015) [16]. It is estimated that every year, due to sickness absence, Poland loses $5 \%$ of its real gross domestic product (GDP) which is calculated at about PLN 71.8-86.2 billion [3].

\section{Rising costs in the private sector}

Regardless of the increasing number of private health insurance and subscriptions, the private sector is also experiencing increasing costs. According to the Mercer report on "Medical trends around the world," the medical trend rate, which shows the increase in costs among insurers and subscription companies, has remained at a high level for the last 3 years: $9.9 \%$ in 2016, 9.5\% in $2017,9.7 \%$ in 2018, and 9.6\% in 2019 (in global terms). In Poland, it is estimated to have reached $7.7 \%$ in 2019. The medical trend rate is an average increase in medical costs, as estimated by respondents (insurance and subscription companies). This trend rate consists of various reasons for the growing medical costs (salaries, the inflation rate, medical technology, non-communicable diseases, etc. [17]).

In this report, Mercer defines 5 main risks that increase medical costs in private medical packages across Europe, in the following order:

risks associated with the cardiovascular system and metabolic diseases,

risks associated with mental/emotional health,

risks associated with nutrition,

occupational risks,

smoking tobacco.

The development of medical technology as well as the overprescribing of medical procedures by doctors are also significant.

Similar results were published in the " 2019 Global Medical Trends Survey Report" by WTW [18]. Respondents assessed the global medical trend rate at $7.3 \%$ in $2016,6.7 \%$ in $2017,7.1 \%$ in 2018 , and $7.6 \%$ in 2019 .

The main reasons for the global increase in costs are: a high use of outpatient and inpatient healthcare services,

- an unnecessary overuse of medical procedures,

unhealthy lifestyles of insured employees,

an insufficient use of preventive examinations.

Among the most common and, at the same time, the most expensive diseases with a growing trend over the next 5 years, insurers in Europe mention:

cardiovascular system diseases,

muscoskeletal system diseases,

cancer,

diabetes and metabolic diseases,

digestive system diseases,

respiratory system diseases,

mental disorders.

It is noticed that mental disorders are becoming increasingly important. In response to the growing demand from employees for treatment, more companies include mental health and stress-related treatment, along with psychotherapy, in the scope of their medical packages. Psychosocial exposures at the workplace have 
a significant impact on employee health and well-being. According to 2007 data, over 40 million employees in European countries suffered from work-related stress, which was the second most frequently reported issue accounting for $50-60 \%$ of absenteeism [19].

The AON study also confirmed a high medical trend rate, which shows an increase in medical costs of healthcare, as reported by contracted medical providers and insurance companies. The factors that increase medical costs are mainly the aging population, unhealthy lifestyles and a growing use of private medical packages financed by employers [20]. The comparison of medical trend rates, as assessed by Mercer, WTW and AON, for the last 4 years is presented in Table 1.

The above reports indicate the need to increase the importance of disease prevention and promotion of healthy lifestyles among employees in order to reduce or avoid cost increases. Given the growing demand for the medical services described above, and the limited supply of services and doctors, investment in prevention is a must.

As in public health, the private sector has also issues with providing services to meet the growing demand and patients' needs. Private medical companies face more and more challenges and expenses. An insufficient number of doctors and longer waiting times are growing issues also in the private sector. In Poland, there are 2.4 doctors per 1000 inhabitants, while the OECD average is 3.4 per 1000 inhabitants [21].

At the same time, an increase is being observed in medical staff salaries and, therefore, prices for private medical packages. The average wage increase in the healthcare sector, as published in the Small Statistical Yearbook, was 3.3\% in 2016, 5\% in 2017, 6.6\% in 2018 , and $10.3 \%$ in 2019 [22]. The increase in salaries in the healthcare sector, as published in another report by GUS, was $6.7 \%$ in 2018 [23]. The same index rate published in 2019 increased to $10.2 \%$ [23].

Private health insurance and medical subscriptions provide a wide scope of services, starting from basic

Table 1. Medical global trend rates according to Mercer, Willis Towers Watson (WTW) and AON reports [17,18,20]

\begin{tabular}{lllll}
\hline \multirow{2}{*}{$\begin{array}{c}\text { Insurance } \\
\text { broker }\end{array}$} & \multicolumn{5}{c}{ Global trend rate } \\
\cline { 2 - 5 } & 2016 & 2017 & 2018 & 2019 \\
\hline Mercer & 9.90 & 9.50 & 9.70 & 9.60 \\
WTW & 7.30 & 6.70 & 7.10 & 7.60 \\
AON & 8.10 & 8.20 & 8.40 & 7.80 \\
\hline
\end{tabular}

healthcare and prevention, through specialist care diagnostics, to physiotherapy and dentistry (usually). This, however, is not all, because there are some medical packages on the Polish market that also cover 1-day surgeries, inpatient care and childbirth. Nevertheless, due to their high prices, these types of products are much less common.

\section{Promotion of healthy lifestyles at the workplace}

Recently, a trend has been observed towards expanding the scope of private medical packages offered to employees [24]. Packages with full and unlimited access to specialist doctors, laboratory and diagnostic tests (including tomography and nuclear magnetic resonance) have already become standard on the employee's market. One can choose the type of the supplier: an insurance company with many medical facilities belonging to different networks or a medical company that also offers medical subscriptions, with its own network of medical facilities (less than in the case of an insurance company). Both of these solutions have their pros and cons, while each supplier faces the same problems of rising costs (and hence prices) and an insufficient number of doctors.

Therefore, employee health management should undoubtedly be a comprehensive activity, consisting of several elements, suited to employees' needs and health issues. Such elements include disease prevention, health promotion at the workplace and broadly understood well-being. To best adapt specific activities to the needs of employees, it is worth preceding any actions with an analysis, e.g., by conducting a survey [25]. The importance of improving employee health and well-being was mentioned by WHO in its 2010 document [26].

While discussing the subject of prevention, one can hardly neglect Lalonde's concept of health fields, according to which our lifestyle is responsible for our health in over $50 \%$, and the environment (including work environment) in 20\%. According to the Global Burden of Disease Study, lifestyles (or behavioral factors) in 2016 were responsible for almost half of all deaths in Poland (48.7\%) [27]. Examples of such behaviors are well known: smoking tobacco (already 4 cigarettes/day significantly increase the risk of death due to coronary heart disease and lung cancer [28]);

improper diet (according to CBOS research, $80 \%$ of respondents are convinced that they eat healthily [29]. At the same time, $42 \%$ of Polish employees eat fruit and vegetables less frequently than once a day [9]. In 2016 obesity concerned $25.2 \%$ of the popula- 
tion aged $\geq 20$ years [30]. Untreated obesity leads to the development of many diseases and is responsible for the major part of medical costs, burdening both the healthcare system and the society [31]);

physical activity (the WHO recommends aerobic training for $150 \mathrm{~min} /$ week (moderate intensity) or $75 \mathrm{~min} /$ week (high intensity), as well as muscle strengthening exercises at least 2-3 times/week [32]. Some exercises performed at the workplace can also help to improve health [33]);

- coping with stress (the scale of exposure and the ways of coping with stress also affect health, both mentally and physiologically [34]). Chronic stress can negatively affect many areas of human health, e.g., by increasing the risk of depression, atherosclerosis or cardiovascular diseases [35].

According to British research, people who perform demanding work with a little sense of control and freedom in making decisions have a $23 \%$ greater risk of heart attack than people in senior decision-making positions [36]. It is an exemplificatory hint for employers to approach the subject of prevention as comprehensively as possible, and to adapt their activities to the needs and health threats among employees, as well as to the specifics of their position.

Taking into account the time employees spend at work, social relations and the obligation to comply with health and safety regulations, workplaces can play an important role in promoting healthy lifestyles [37], given especially that work intensity in most European countries has increased over the past 2 decades [38]. The workplace is, therefore, a key place affecting employee health.

According to a report prepared by the Nofer Institute for Occupational Medicine, entitled "Management of personnel health in the context of aging population," the promotion of health at the workplace caused a decrease in the level of sickness absence by $25 \%$ in the surveyed companies, and the investment in health-oriented activities addressed to employees brought a return of over 2.5 times [39].

Research conducted on a sample of 1000 companies and published in the above-mentioned report revealed that half of the companies, after implementing health-related programs, recorded higher work efficiency, $49 \%$ reported improvement of employee health, $47 \%$ increased the identification of employees with the company, $43 \%$ reduced sickness absence, $42 \%$ improved the lifestyle of their employees, and $40 \%$ noticed that it was easier for them to attract new employees. Well-be- ing was recognized by employers as one of the most important trends in human resources in 2018 in Poland, and programs supporting employee well-being as the best investment. Over the next 3 years, 54\% of Polish companies are considering implementing elements of a well-being program. In turn, data disclosed by the $\mathrm{Na}-$ tional Center for Workplace Health Promotion indicate that every third medium-sized and large company in Poland has increased its involvement in the health of employees in recent years [40].

\section{CONCLUSIONS}

The conducted analysis shows that the demand for private medical care is rising and that more employers are willing to invest in private medical care for their employees. Given the rising demand and an insufficient number of specialists, access to medical services is deteriorating, and the premium rates and costs are rising. Unhealthy workers generate costs due to their absenteeism, lower productivity and a higher utilization of medical services [41]. As the medical care focused on treating diseases alone is not enough to keep employees healthy for as long as possible, a response to the aging population [42], the growing demand for medical services, and also the continually rising costs should be made through prevention and health promotion, adapted to the current needs and health problems of employees [43]. Taking into consideration the number of workforce in Poland, along with its contribution to the economic development, the estimated productivity losses due to absenteeism are a significant part of the GDP [44]. Therefore, empowering employee health is important not only for companies and individuals, but also for building the social and economic capital of the country.

\section{ACKNOWLEDGEMENTS}

The authors would like to thank Dominik Olejniczak, holder of post-doctoral degree, for his support and guidance in their first steps in scientific activity.

\section{REFERENCES}

1. Polish Chamber of Insurance [Internet]. The Chamber; 2019 [cited 2019 Oct 15]. [Number of Poles with private health insurance exceeded 2,5 mln]. Available from: https:// piu.org.pl/ponad-dwa-i-pol-miliona-polakow-z-polisa. Polish. 
2. Statistics Office [Internet]. The Office; 2016 [cited 2019 Oct 16]. [Health care in households]. Available from: https:// stat.gov.pl/obszary-tematyczne/zdrowie/zdrowie/ochrona-zdrowia-w-gospodarstwach-domowych-w-2016-r-,2,6. html. Polish.

3. Polish Chamber of Insurance [Internet]. The Chamber; 2018 [cited 2019 Oct 10]. [Financing of employees' healthcare. How to take care of the health of the key social group for development?]. Available from: https://piu.org.pl/wp-content/ uploads/2019/04/Raport-zdrowotny-PIU.pdf. Polish.

4. Watch Health Care Barometer [Internet]. Report on changes in the availability of guaranteed health services in Poland no. 19/15/02/2019. Updates on December/January 2019 [cited 2019 Oct 10]. [Report on changes in the availability of guaranteed health services in Poland no 19/15/02/2019]. Available from: http://www.korektorzdrowia.pl/barometr/. Polish.

5. Pracuj.pl [Internet]. [Benefits - what motivates employees?] [cited 2019 Oct 9]. Available from: http://media. pracuj.pl/26283-benefity-czyli-co-motywuje-pracownikow. Polish.

6. [Act on 27 June, 1997 on occupational medicine service. J Laws 1997, No. 97, item 593]. Polish.

7. Peckham T, Baker M, Camp J, Kaufman J, Seixas N. Creating a Future for Occupational Health. Ann Work Exposures Health. 2017;61(1):3-15, https://doi.org/10.1093/annweh/wxw011.

8. Kozioł L, Muszyński Z, Kozioł M. [The concept of absenteeism management system in the enterprise]. Tarnów: Scientific Notebooks of the Małopolska University of Economics; 2016. Polish.

9. Puchalski K, Korzeniowska E. [Health promotion at workplace: support for healthy eating and physical activity for employees]. Łódź: Nofer Institute of Occupational Medicine; 2017. Polish.

10. Social Security Institution [Internet]. The Institution; 2019 [cited 2019 Oct 4]. [Sick absence in 2018]. Available from: https://www.zus.pl/documents/10182/39590/Absencja + chorobowa $+w+2018+$ roku.pdf/c70b0e4a-2f6f-dbb97dde-79cf6ca334f8. Polish.

11. Social Security Institution [Internet]. The Institution; 2019 [cited 2019 Oct 4]. [Analysis of the reasons for sickness absence in the years 2012-2016]. Available from: https://www. zus.pl/documents/10182/39590/Analiza+przyczyn+absencji+chorobowej+w+latach+2012-2016.pdf/c045c950143c-4b25-98d7-e0bf5d5dae2e. Polish.

12. Łyszczarz B. [Assessment of the costs of heart failure in Poland from the perspective of the state economy]. Institute of Innovative Economy; 2017, https://doi.org/10.13140/ RG.2.2.35711.51364. Polish.
13. Supreme Audit Office [Internet]. The Office [cited 2019 Oct 4]. [Prevention and treatment of type 2 diabetes]. Inspection carried out in 2015-2017 (first half). Available from: https://www.nik.gov.pl/kontrole/P/17/057/. Polish.

14. Chojnacki M, Chromiec Z, editors. [Digital sources in the service of patients, about the use of data potential in healthcare sector] [Internet]. Leslaw Paga Foundation; 2019 [cited 2019 Oct 16]. Alumni Report of the Health Care Leaders project. Available from: http://paga.org.pl/upload/source/ RAPORT\%20LOZ.pdf.

15. [Regulation of the Minister of Labour and Social Policy of 18 December 1998 on the detailed rules for determining the basis for calculating contributions for retirement and disability pension insurance. J Laws 1998, No. 161, item 1106]. Polish.

16. Rydlewska-Liszkowska I. [Models of workers' health and safety insurance in the selected European Union member states: certain economic problems]. Med Pr. 2007;58(6): 511-9. Polish.

17. Mercer [Internet]. Mercer; 2019 [cited 2019 Nov 10]. 2019 medical trends around the world. Available from: https://www.mercer.com/our-thinking/health/mercermarsh-benefits-medical-trends-survey-2019.html.

18. Willis Tower Watson [Internet]. Willis Tower Watson; 2019 [cited 2019 Nov 14]. 2019 global medical trends survey report. Available from: https://www.willistowerswatson.com/ en-ID/insights/2018/11/2019-global-medical-trends-survey-report.

19. Merecz-Kot D, Waszkowska M, Mościcka-Teske A, Potocka A, Drabek M, Wężyk A. [Internet]. [A comprehensive prevention program on psychosocial risks in the work environment]. Łódź: Nofer Institute of Occupational Medicine [cited 2019 Oct 15]. Available from: http://www.programyzdrowotne.pl/Portals/1/Files/PDF/programy/psychospoleczne.pdf.

20. AON [Internet]. AON, Global Benefits [cited 2019 Nov 14]. 2019 global medical trend rates report. Available from: https://www.aon.com/getmedia/0c375f10-3b16-4d2da452-4ae86968525b/2019-Global-Medical-Trend-Report. pdf.aspx.

21. Organisation for EconomicCo-operation and Development [Internet]. The Organisation; 2019 [cited 2019 Nov 4]. Health at a Glance: Europe 2018. Available from: https:// www.oecd.org/health/health-at-a-glance-europe-23056 088.htm.

22. Statistics Office [Internet]. The Office; 2016 [cited 2019 Nov 14]. [Small Statistical Yearbook]. Available from: https:// stat.gov.pl/obszary-tematyczne/roczniki-statystyczne/ roczniki-statystyczne/maly-rocznik-statystyczny-polski-2019,1,21.html. Polish. 
23. Statistics Office [Internet]. The Office; 2017 [cited 2019 Nov 12]. [Employment and wages in the national economy]. Available from: https://stat.gov.pl/obszary-tematyczne/ rynek-pracy/pracujacy-zatrudnieni-wynagrodzenia-koszty-pracy/zatrudnienie-i-wynagrodzenia-w-gospodarcenarodowej-w-2017-roku,1,29.html. Polish.

24. Polish Chamber of Insurance [Internet]. The Chamber; 2018 [cited 2019 Nov 4]. [We have spent almost PLN $600 \mathrm{mln}$ on private health insurance]. Available from: https://piu. org.pl/prawie-600-mln-zl-wydalismy-na-ubezpieczeniazdrowotne/. Polish.

25. Chetty L. An evaluation of the health and wellbeing needs of employees: An organizational case study. J Occup Health. 2017;59(1):88-90, https://doi.org/10.1539/joh.160197-BR.

26. World Health Organization [Internet]. The Organization; 2010 [cited 2019 Nov 5]. Healthy Workplace: A Model for Action. Available from: https://www.who.int/occupational_health/publications/healthy_workplaces_model_action.pdf.

27. Śliż D, Mamcarz A. [Lifestyle medicine]. Warsaw: Medical University of Warsaw; 2018. Polish.

28. Bjartveit $\mathrm{K}$, Tyerdal A. Health consequences of smoking 1-4 cigarettes per day. Tob Control. 2005;14(5):315-20, https://doi.org/10.1136/tc.2005.011932.

29. CBOS [Internet]. CBOS; 2019 [cited 2019 Oct 27]. [How healthy eat Poles?]. Available from: https://www.cbos.pl/ SPISKOM.POL/2019/K_106_19.PDF. Polish.

30. Kraciuk J. [Food security of the European Union countries]. Annals PAAAE. 2017;XIX(3):150-5, https://doi. org/10.5604/01.3001.0010.3238.

31. Tremmel M, Gerdtham UG, Nilsson PM, Saha S. Economic Burden of Obesity: A Systematic Literature Review. Int J Environ Res Public Health. 2017;14(4):435, https://doi. org/10.3390/ijerph14040435.

32. World Health Organization [Internet]. The Organization; 2020 [cited 2019 Oct 27]. Global recommendations on physical activity for health, recommended levels of physical activity for adults aged 18-64 years. Available from: https:// www.who.int/dietphysicalactivity/factsheet_recommendations/en/.

33. Conn VS, Hafdahl A, Cooper P, Brown L, Lusk S. Metaanalysis of workplace physical activity interventions. Am J Prev Med. 2009;37(4):330-9, https://doi.org/10.1016/ j.amepre.2009.06.008.
34. Yaribeygi H, Panahi Y, Sahraei H, Johnston TP, Sahebkar A. The impact of stress on body function: A review. EXCLI J. 2017;16:1057-72, https://doi.org/10.17179/excli2017-480.

35. Mariotti A. The effects of chronic stress on health: new insights into the molecular mechanisms of brain-body communication. Future Sci OA. 2015;1(3):FSO23, https://doi. org/10.4155/fso.15.21.

36. Kivimaki M, Nyberg ST, Batty GD, Fransson El, Heikkila K, Alfredsson L, et al. Job strain as a risk factor for coronary heart disease: a collaborative meta-analysis of individual participant data. Lancet. 2012;380(9852):1491-7, https:// doi.org/10.1016/S0140-6736(12)60994-5.

37. Gniazdowski A. [Health promotion at workplace]. Łódź: Nofer Institute of Occupational Medicine; 1997. Polish.

38. Namysł A, Kazenas A, Bugajska J [Health promotion at workplace - investment in empoyee's health and company's capital]. Warsaw: Central Institute for Labor Protection National Research Institute; 2012. Polish.

39. Goszczyńska E, Korzeniowska E, Puchalski K. [Personnel health management in the context of an aging population. Report from a representative survey of 1,000 medium and large workplaces in Poland]. Łódź: Nofer Institute of Occupational Medicine; 2018. Polish.

40. Puchalski K, Korzeniowska E. [Health promotion in medium-sized and large companies in Poland in 2017 - activities, implementation, effects and difficulties]. Med Pr. 2019;70(3):275-94, https://doi.org/10.13075/mp.5893.008 02. Polish.

41. McLellan RK. Work, health and worker well-being: roles and opportunities for employers. Health Affairs. 2017; 36(2):206-13, https://doi.org/10.1377/hlthaff.2016.1150.

42. Magnavita N, Sakowski P, Capitanelli I, La Milia D, Moscato U, Poscia A, et al. Health promotion for the aging workforce in Poland. Int J Occup Med Environ Health. 2018; 31(6):753-61,https://doi.org/10.13075/ijomeh.1896.01207.

43. Tremblay P, Nobrega S, Davis L, Erck E, Paunnett L. Healthy Workplace? A survey of Massachusetts Employers. Am J Health Promot. 2013;27(6):390-400, https://doi. org/10.4278/ajhp.110216-QUAN-72.

44. Genowska A, Fryc J, Pinkas J, Jamiołkowski J, Szafraniec K, Szpak A, et al. Social costs of loss in productivity-related absenteeism in Poland. Int J Occup Med Environ Health. 2017;30(6):917-32, https://doi.org/10.13075/ ijomeh.1896.01123.

This work is available in Open Access model and licensed under a Creative Commons Attribution-NonCommercial 3.0 Poland License - http://creativecommons.org/licenses/by-nc/3.0/pl/deed.en. 